\title{
EL PROCESO DE ADOPCIÓN DE INNOVACIONES EN EL CULTIVO DEL ARROZ EN ECUADOR
}

\author{
$\underline{\text { Silverio Alarcón }}^{\mathrm{a}^{*}}$, Victor H. Lema ${ }^{\mathrm{b}}$
}

a Departamento de Economía Agraria, Estadística y Gestión de Empresas, Universidad Politécnica de Madrid, (Madrid, silverio.alarcon@upm.es).

a Ministerio de Agricultura y Ganadería, Ecuador, (Quito,vlemac@mag.gob.ec).

\section{Resumen}

El arroz es un cultivo que contribuye notablemente tanto a la seguridad alimentaria como a garantizar unos niveles adecuados de renta a los agricultores. Esto motiva los esfuerzos que se realizan por difundir técnicas que aumentan la producción, y son respetuosas con el medio ambiente y asequibles a pequeños agricultores. El objetivo de este trabajo es estudiar el proceso de adopción de innovaciones en el cultivo del arroz en Ecuador. Se han seleccionado cuatro prácticas que incrementan el rendimiento y mejoran la gestión del agua y otros recursos naturales: nivelación del terreno, semilla certificada, siembra de plántulas mediante el trasplante con distanciamiento y uso de maquinaria para cosechar. Para cada una de ellas se estudian factores que inciden en su adopción: capital humano, capital social y apoyo institucional a la agricultura. Además, se analiza la interrelación de unas prácticas con otras. La estimación de modelos probit multivariantes muestra que la educación es el principal factor que aumenta la probabilidad de adoptar estas prácticas. Y con incidencia desigual se encuentran el asociacionismo, el acceso al crédito y la contratación de seguro agrario. Las complementariedades encontradas entre distintas prácticas apuntan a la conveniencia de fomentarlas de forma conjunta para aprovechar sus sinergias.

Palabras clave: arroz, interrelación entre técnicas sostenibles, capital humano

\section{Introducción}

Junto con otros cereales como el trigo o el maíz, el arroz es uno de los cultivos básicos en la alimentación mundial. En Ecuador el arroz es el segundo principal cultivo transitorio por superficie, por detrás del maíz. En 2019 se sembraron 288.797 ha con una producción de 1.668.523 $t$ [MAG-SIPA (2020)], que generaron 77.450 plazas de empleo [INIEC (2020)], y una participación del 3.6\% en el Valor Agropecuario Bruto.

Tanto a nivel nacional como internacional se realizan esfuerzos para difundir resultados de investigación y prácticas innovadoras con la finalidad de que los agricultores introduzcan estas mejoras en sus cultivos y redunden en mayores producciones con menos recursos, y permita obtener un menor costo unitario de producción. Así, el uso de tecnologías de gestión eficiente del agua contribuye a la seguridad alimentaria desde un planteamiento respetuoso con el medioambiente [Ali et al. (2018)]. Este trabajo se centra en analizar algunas de estas prácticas distintas a las convencionales en el cultivo del arroz en Ecuador, que son adoptadas con distinta intensidad por parte de los agricultores.

Las prácticas que se han seleccionado son: nivelación del terreno, que lleva a una gestión más eficiente del agua, al reducir sus pérdidas [Ali et al. (2018)]; uso de semilla certificada, que mejora la germinación y la sanidad vegetal del cultivo; trasplante de plántulas, en lugar de sembrar directamente a voleo o chorrillo, que implica una mayor mano de obra pero que contribuye también a una buena germinación; uso de maquinaria para cosechar, que permite tener menor pérdida de grano, y por tanto disminuye desperdicios y ahorra recursos.

En este trabajo, el objetivo es identificar los factores específicos de los agricultores y de las instituciones que están relacionados con la adopción de estas prácticas culturales. En concreto, las variables explicativas que se han tenido en cuenta tratan de recoger el capital humano (educación, experiencia, capacitación), el capital social (asociacionismo), y el apoyo institucional a la agricultura (ayudas del gobierno, acceso al crédito y contratación de seguro). La principal aportación de este trabajo es que se consideran además las interacciones de unas prácticas con otras. En otras palabras, se ha estimado un sistema de ecuaciones probit multivariante [Greene (2012)]. Así se evitan sesgos de especificación y se obtienen las correlaciones de los términos de error de cada ecuación, de forma que se puede contrastar si efectivamente las decisiones de uso de tecnologías son independientes unas de otras, o por el contrario son complementarias o sustitutivas [Ward et al. (2018)]. 


\section{Antecedentes}

Las principales provincias productoras son Guayas $(73,92 \%)$ y Los Ríos (20,55\%), y con mucha menos importancia se cultiva en Loja (2,81\%), El Oro (2,10\%) y Manabí (0,62\%) (MAG-SIPA, 2020). En cuanto a la importancia del cultivo de arroz en la seguridad alimentaria según la Encuesta de Condiciones de Vida 2014 realizada por el Instituto Nacional de Estadísticas y Censos, se determinó que el consumo de arroz (demanda) a nivel nacional de los hogares es de $45.47 \mathrm{~kg} / \mathrm{año}$, frente a una oferta de $51 \mathrm{~kg} / \mathrm{año}$. Esto evidencia la existencia de una oferta disponible suficiente para garantizar el consumo de los habitantes de Ecuador de la gramínea.

Una parte importante de la investigación relativa al cultivo del arroz y los procesos de adopción de innovaciones se ha centrado en el uso de semilla certificada y nuevas variedades. En las últimas décadas, sin embargo, ha aumentado el interés por innovaciones que son más sostenibles con el medio ambiente y más asequibles para los pequeños agricultores. Por ejemplo, estudios sobre adopción de prácticas de gestión del agua [Ali et al. (2018); Aryal et al. (2018)] o adquisición o uso de maquinaria.

Dado que las decisiones de adopción de innovaciones se pueden tratar como variables dicotómicas, los modelos econométricos más usados han sido logit o probit con variables binarias de nuevas variedades, uso de semilla certificada, nivelación del terreno [Ali et al. (2018)], prácticas de gestión eficiente del agua, entre otros. Sin embargo, cuando el interés es analizar un conjunto de tecnologías presumiblemente complementarias se pueden seguir distintas estrategias. Una de ellas es estudiar la interrelación entre las distintas decisiones mediante modelos probit multivariantes [Ward et al. (2018)]. De esta forma, se obtiene información sobre los factores relacionados con la adopción de innovaciones, y además sobre si se toman decisiones de forma simultánea, o existen relaciones complementarias o sustitutivas entre distintos tipos de prácticas. Es decir, se mejora la capacidad de modelizar un proceso de decisión complejo.

\section{Datos}

Los datos utilizados han sido obtenidos el Ministerio de Agricultura y Ganadería a través del SIPA, Sistema de Información Pública Agropecuaria del Ecuador [http://sipa.agricultura.gob.ec/index.php].

En este trabajo se seleccionaron aquellas prácticas culturales en las que se observó alguna incidencia significativa sobre el aumento del rendimiento neto y con proporciones de adopción significativas (Cuadro 1).

Cuadro 1. Estadísticos de prácticas innovadoras (variables dependientes) y rendimiento medio

\begin{tabular}{lllll}
\hline & & N & Porcentaje & Rendimiento medio (t/ha) \\
\hline Nivelación terreno & No & 519 & 43,91 & 5,25 \\
& Sí & 663 & 56,09 & 6,67 \\
Semilla certificada & No & 813 & 68,78 & 5,72 \\
& Sí & 369 & 31,22 & 6,76 \\
Siembra distanciamiento & No & 424 & 35,87 & 5,33 \\
& Sí & 758 & 64,13 & 6,44 \\
Maquinaria cosecha & No & 391 & 33,08 & 5,93 \\
& Sí & 791 & 66,92 & 6,10 \\
\hline
\end{tabular}

Fuente: Elaboración propia a partir de MAG-SIPA (2020).

A partir de la literatura de adopción de prácticas innovadoras en el arroz se han seleccionado variables explicativas de capital humano, capital social e instituciones. Para el capital humano se han considerado: años de educación, si ha recibido capacitación, así como la edad del productor como indicador de su experiencia. Para el capital social se ha usado la variable de pertenencia a asociación. Otros factores institucionales de apoyo a la agricultura se caracterizan a partir de variables de subvenciones (Ayudas), financiación ajena (Crédito) y seguro agrario (Seguro). Como variable de control se han tomado el tamaño de la explotación mediante superficie total del predio. 


\section{Resultados}

Cuadro 2. Probit multivariante

\begin{tabular}{|c|c|c|c|c|}
\hline & Nivelación & Semilla & Siembra & Cosecha \\
\hline \multirow[t]{2}{*}{ constante } & 0,0843 & $-1,0033 * * *$ & $0,4991 * * *$ & $0,4783 * *$ \\
\hline & $(0,1846)$ & $(0,1980)$ & $(0,1914)$ & $(0,1984)$ \\
\hline \multirow[t]{2}{*}{ Años estudio } & $0,0284 * * *$ & $0,0430 * * *$ & $-0,0111$ & 0,0173 \\
\hline & $(0,0107)$ & $(0,0112)$ & $(0,0111)$ & $(0,0111)$ \\
\hline \multirow[t]{2}{*}{ Capacitación } & $-0,1179$ & 0,1038 & $-0,0186$ & $-0,0400$ \\
\hline & $(0,1010)$ & $(0,1046)$ & $(0,1082)$ & $(0,1067)$ \\
\hline \multirow[t]{2}{*}{ Edad } & 0,0004 & 0,0024 & $0,0055^{*}$ & $-0,0035$ \\
\hline & $(0,0028)$ & $(0,0030)$ & $(0,0029)$ & $(0,0029)$ \\
\hline \multirow[t]{2}{*}{ Asociación } & $0,2080 * *$ & $-0,0807$ & $-0,0100$ & $-0,0008$ \\
\hline & $(0,0907)$ & $(0,0950)$ & $(0,0927)$ & $(0,0931)$ \\
\hline \multirow[t]{2}{*}{ Ayudas } & $-0,1194$ & $-0,1126$ & $-0,1227$ & $-0,2208 *$ \\
\hline & $(0,1108)$ & $(0,1139)$ & $(0,1155)$ & $(0,1161)$ \\
\hline \multirow[t]{2}{*}{ Crédito } & $0,2583 * *$ & $0,2312 *$ & $0,2333^{*}$ & 0,0148 \\
\hline & $(0,1249)$ & $(0,1261)$ & $(0,1266)$ & $(0,1282)$ \\
\hline \multirow[t]{2}{*}{ Seguro } & 0,1369 & $0,9689 * * *$ & $-0,0336$ & $-0,0826$ \\
\hline & $(0,1742)$ & $(0,1839)$ & $(0,1772)$ & $(0,1794)$ \\
\hline \multirow[t]{2}{*}{$\log ($ Superficie $)$} & $-0,1328 * * *$ & $-0,0062$ & $-0,2278 * * *$ & $0,0683^{*}$ \\
\hline & $(0,0407)$ & $(0,0416)$ & $(0,0420)$ & $(0,0385)$ \\
\hline \multirow[t]{2}{*}{ r_Nivelación,Semilla } & 0,0759 & & & \\
\hline & $(0,0502)$ & & & \\
\hline \multirow[t]{2}{*}{ r_Nivelación,Siembra } & $0,2166 * * *$ & & & \\
\hline & $(0,0466)$ & & & \\
\hline \multirow[t]{2}{*}{ r_Nivelación,Cosecha } & $0,2091 * * *$ & & & \\
\hline & $(0,0479)$ & & & \\
\hline \multirow[t]{2}{*}{ r_Semilla, Siembra } & $0,4054 * * *$ & & & \\
\hline & $(0,0462)$ & & & \\
\hline \multirow[t]{2}{*}{ r_Semilla,Cosecha } & $-0,0049$ & & & \\
\hline & $(0,0523)$ & & & \\
\hline \multirow[t]{2}{*}{ r_Siembra,Cosecha } & $0,1511 * * *$ & & & \\
\hline & $(0,0510)$ & & & \\
\hline Loglikelihood & $-2926,0384$ & & & \\
\hline Observaciones & 1182 & & & \\
\hline
\end{tabular}

Fuente: Elaboración propia a partir de MAG-SIPA. (2020). * $\mathrm{p}<0,1, * * \mathrm{p}<0,5, * * * \mathrm{p}<0,01$

Las variables explicativas de capital humano son las que presentan mayor relación positiva y significativa con las adopciones de innovaciones consideradas, y en especial años de estudio (Cuadro 2). Un mayor nivel de educación implica mayor probabilidad de nivelar el terreno y usar semilla certificada. La variable capacitación no es significativa, y además presenta signos negativos, distintos de los esperados, de forma contraria a otros estudios donde sí se menciona un papel importante de las políticas de extensión agraria. Por su parte, la edad presenta coeficientes próximos a cero y no significativos, y no parece ser un freno en el sistema del cultivo del arroz. La variable asociación, como indicador del capital social, muestra significatividad positiva con nivelación del terreno. 
Las variables de apoyo institucional a la agricultura revelan que las ayudas del Gobierno presentan relaciones negativas pero en ningún caso se alcanza significatividad. Sin embargo, el acceso al crédito sí muestra una relación positiva y significativa con nivelación del terreno, y en menor medida con semilla certificada y siembra por distanciamiento. Por su parte, la proporción de productores que contratan seguro es baja pero está claramente en relación con el uso de semilla certificada.

En cuanto a los coeficientes de correlación de unas prácticas con otras se han encontrado solamente relaciones de complementariedad. Cuatro de seis coeficientes de correlación son positivos y significativos. No se han encontrado relaciones de sustitución, como sí se obtiene en otros trabajos [Ward et al. (2018)]. A nivel práctico, estos resultados ponen de manifiesto la existencia de procesos de decisión conjuntos en la planificación del cultivo del arroz en Ecuador. Y avalarían que la decisión de nivelar el terreno la realizan muchos productores porque es una práctica que facilita la siembra por distanciamiento y el uso de cosechadora. Es decir, se generan sinergias entre estas tres actividades, y probablemente inciden en una mejor gestión de los recursos y mayor rentabilidad. De la misma forma, se puede hablar de un elevado nivel de complementariedad entre el uso de semilla certificada y la siembra por distanciamiento.

\section{Conclusiones}

Este estudio ha encontrado evidencias estadísticas de la existencia de relaciones de complementariedad entre las prácticas agrícolas de modernización del cultivo del arroz en Ecuador. Se constata que la adopción de prácticas innovadoras es un proceso de decisión complejo influenciado por varios factores e interrelacionado.

En cuanto a las fortalezas del sistema de producción del cultivo de arroz en Ecuador, destaca la importancia de la educación como factor de cambio y modernización, así como del crédito, las asociaciones y el seguro. Es más, dado que unas prácticas están interconectadas con otras, se puede hablar de efectos directos e indirectos de las variables explicativas.

Se recomienda fortalecer e incentivar el asociacionismo, y aumentar y facilitar el acceso al crédito. Estas acciones deben dirigirse hacia las prácticas de nivelación del terreno y siembra por distanciamiento. Es decir, se debería focalizar en promover una gestión eficiente del agua de riego desde el inicio de la preparación del cultivo, como base para desarrollar posteriormente una gestión adecuada de otros factores productivos (semilla, siembra, uso de maquinaria, fertilizantes, malas hierbas, enfermedades).

\section{Bibliografía}

Ali, A., Hussain, I. y Erenstein, O. (2018). Laser-land leveling adoption and its impact on water use, crop yields and household income: Empirical evidence from the rice-wheat system of Pakistan Punjab. Food Policy, 77, 19-32.

Aryal, J. P., Rahut, D. B., Jat, M. L., Maharjan, S. y Erenstein, O. (2018). Factors determining the adoption of laser land leveling in the irrigated rice-wheat system in Haryana, India. Journal of Crop Improvement, $32(4), 477-492$.

Greene, W. H. (2012). Econometric analysis (7th ed.). Pearson.

INIEC. (2020). Encuesta de superficie y producción agropecuaria continua (espac) 2019. Inistituo Nacional de Estadísticas y Censos, Gobierno de la República del Ecuador.

MAG-SIPA. (2020). Sistema de información pública agropecuaria (sipa). Ministerio de Agricultura y Ganadería, Gobierno de la República del Ecuador. http://sipa.agricultura.gob.ec/index.php

Ward, P. S., Bell, A. R., Droppelmann, K. y Benton, T. G. (2018). Early adoption of conservation agriculture practices: Understanding partial compliance in programs with multiple adoption decisions. Land Use Policy, 70, 27-37. 